EDITORIAL

\title{
Conocimiento y comunidad escolar: Procesos de interpretación de las dinámicas relacionales escolares en la educación básica como configuración cognitiva situada
}

\author{
COORDINADORES \\ Sergio Toro Arévalo ${ }^{a}$, Javier F. A. Vega Ramírez \\ anniversidad Austral de Chile. Correo electrónico: seatoro@gmail.com \\ bUniversidad Austral de Chile. Correo electrónico: javier.vega@uach.cl
}

Durante los últimos años, se han venido desarrollando nuevas aproximaciones al fenómeno educativo, otorgándosele particular importancia a un acercamiento en función de la dimensión encarnada del aprendizaje en contextos escolares situados de diferentes dependencias administrativas. Un aspecto constatado, el cual no carece de obviedad, se refiere a que los procesos vividos por parte del grupo-curso sobrepasan el espaciotiempo desarrollado en el aula; estos también se despliegan en los tiempos de recreo, los grupos de interés, las actividades complementarias, entre otros. Por tanto, en estos otros espacios cotidianos y frecuentes, pero que no coinciden con el espacio tradicional de aula, es posible comprometer recursos para la consecución de logros y desarrollo de tareas o actividades que se demanden. Lo anterior, tomando en consideración que para ciertos niños la asistencia a la escuela, sobre todo en esos espacio-tiempo, significa la posibilidad de realización de sus sueños más sentidos. Así, la escuela, como comunidad de relaciones en función del aprendizaje-enseñanza, contiene posibilidades que pueden ser reconocidas como generadoras de ambientes de desarrollo que superan muchas veces lo proyectado de forma tradicional a través del conjunto de relaciones que se establece. En este sentido, se puede generar un escenario propicio para describir comprensivamente la cotidianidad escolar mediante diversas investigaciones, si se parte de la premisa que la institución escolar reproduce, mantiene o altera los ciclos e imaginarios y prácticas sociales, en cuanto a la perspectiva relacional.

De acuerdo a Morin (2007), el mundo educativo escolar tradicionalmente potencia preferentemente el desarrollo intelectual, “(...) la inteligencia que no sabe hacer otra cosa que separar, romper lo complejo del mundo en fragmentos disociados, fraccionar los problemas, convertir lo multidimensional en unidimensional, atrofiar las posibilidades de comprensión y de reflexión": (p. 15). Por su parte, desde la perspectiva de las relaciones humanas, esto se condice con una forma de patriarcado, caracterizado por "su visión 
determinista, mecanicista, cuantitativa y formalista, ignoran, ocultan o disuelven todo lo que es subjetivo, afectivo, libre, creador" (p. 16). De ahí la necesidad de documentar lo vivido por adultos, adultas e infantes de una manera compleja. Nos encontramos, entonces, en una especie de paradoja tanto vivencial como epistemológica. Ello obliga a profundizar en su comprensión e interpretación, desde el conocimiento que genera y desde las contradicciones asumidas y vivenciadas por sus integrantes. Por lo señalado, conviene una aproximación que nos lleve a plantearnos categorías de investigación de profundidad diferente que den cuenta tanto de la complejidad del proceso como de la distinción que pretendemos abarcar.

En esta línea se recoge el planteamiento de Claro (2011), desde un enfoque centrado en la Gestión Escolar, que incorpora el tono de la relacionalidad en diferentes niveles de la comunidad escolar, a saber, lo administrativo, didáctico curricular y el clima escolar. Dicho desafío puede ser asumido desde la experiencia situada de los actores que se desenvuelven en la cotidianidad de la escuela. Observar sus apreciaciones, sus relatos, sus percepciones e imaginarios colectivos sobre el vivir gran parte de su día en el espacio-tiempo escolar se convierte en una posibilidad altamente atractiva y necesaria en un derrotero educativo, en la dimensión política, cultural y, por consecuencia, en la dimensión educativa. Es así como la acción y la palabra, como una virtualidad de lo que se vive, nos genera ciertas aproximaciones de base para describir la fenomenología de la escuela.

Como una forma de desarrollar esta potencialidad investigativa, ofrecemos en el presente número un conjunto de investigaciones y revisiones que nos permitirán profundizar en el mundo escolar a través de la configuración cognitiva situada, la que nos permite comprender y comprendernos como actores y actuantes del mundo educativo. De esta forma, a través de artículos ofrecidos por profesores y profesoras de diversas universidades y centros educativos ubicadas en Chile, Brasil, Colombia y España, podemos configurar un panorama amplio de las posibilidades de profundización del fenómeno educativo.

Agradecemos profundamente el esfuerzo, compromiso, capacidad para desafiarse cada día en el trabajo con los estudiantes, así como agradecemos el apoyo que ha otorgado la Comisión Nacional de Ciencia y Tecnología, particularmente través de su Fondo Nacional de Desarrollo Científico y Tecnológico (Fondecyt), tanto en el apoyo a algunas de las investigaciones que aquí presentamos como a la publicación de este número.

Finalmente, agradecemos a todos y todas quienes configuramos el complejo entramado relacional que llamamos educación: profesores, profesoras, asistentes, estudiantes, familia y todos quienes contribuyen a recrear y renovar la experiencia educativa en los espacios de generación de experiencias que superan ampliamente el espacio tradicional del aula y que permiten desarrollar dinámicas relacionales en la educación básica como configuración cognitiva situada.

\section{REFERENCIAS BIBLIOGRAFICAS}

Morin, E. (2007). La cabeza bien puesta. Repensar la reforma. Reformar el pensamiento. Buenos Aires: Ediciones Nueva Visión.

Claro, S. (2011). Clima escolar y desarrollo integral de niñas y niños. Santiago: Editorial RIL. 